\title{
The physicochemical, sensory evaluation and glycemic load of stingless bee honey and honeybee honey
}

\author{
${ }^{1}$ Raja Nurfatin, R.M.Y., ${ }^{2}$ Norhayati, M.K., ${ }^{2}$ Mohd Fairulnizal, M.N., ${ }^{3}$ Hadi, N., \\ ${ }^{4}$ Abdul Manam, M., ${ }^{1}$ Mohd. Zin, Z. and ${ }^{1, *}$ Yusof, H.M. \\ ${ }^{l}$ Faculty of Fisheries and Food Science, Universiti Malaysia Terengganu, 21030 Kuala Nerus, \\ Terengganu, Malaysia \\ ${ }^{2}$ Nutrition Unit, Nutrition, Metabolism and Cardiovascular Research Centre, Level 3, Block C7, Institute \\ for Medical Research, National Institutes of Health Complex, No.1, Jalan Setia Murni U13/52, Seksyen U \\ 13, Bandar Setia Alam, 40170 Shah Alam, Selangor, Malaysia \\ ${ }^{3}$ Faculty of Health Science, Universiti Sultan Zainal Abidin, Gong Badak, 21300 Kuala Nerus, \\ Terengganu, Malaysia \\ ${ }^{4}$ Faculty of Islamic Contemporary Studies, Universiti Sultan Zainal Abidin, Gong Badak, 21300 Kuala \\ Nerus, Terengganu, Malaysia
}

\author{
Article history: \\ Received: 1 July 2020 \\ Received in revised form: 10 \\ August 2020 \\ Accepted: 2 September 2020 \\ Available Online: 5 \\ December 2020
}

\section{Keywords:}

Physicochemical,

Sensory evaluation,

Glycemic load,

Stingless bee honey,

Honeybee honey

\section{DOI:}

https://doi.org/10.26656/fr.2017.5(1).316

\begin{abstract}
Honey is a widely consumed functional food which has a valued place in traditional medicine. The purpose of this study was to compare the physicochemical properties, sensory evaluation, and glycemic load of honeybee honey and stingless bee honey. Physicochemical parameters include moisture, ash, $\mathrm{pH}$, free acidity, electrical conductivity and sugar content which were determined by following the International Honey Commission methods. Ten subjects were selected for glycemic index study. For oral glucose tolerance test (OGTT), about $50 \mathrm{~g}$ of pure glucose in $250 \mathrm{~mL}$ of water was given to subject while $25 \mathrm{~g}$ of pure glucose in $250 \mathrm{ml}$ water as a reference food. The blood glucose response was measured based on the incremental area under curve (IAUC) and compared to that of $25 \mathrm{~g}$ of available carbohydrate from glucose. Results indicated that the moisture content $(29.5 \%$ vs $28.0 \%)$, free acidity $(84.5$ vs 73.5$)$ and total carbohydrate ( 64.33 vs 50.35 ) of honeybee honey was significantly (all $p<0.05$ ) higher as compared to stingless bee honey, with no significant differences in ash content, $\mathrm{pH}$ and electrical conductivity between both honey $(\mathrm{p}>0.05)$. Their ash content is closely similar, which might be due to a similar geographical source, namely the Marang area. In terms of sensory evaluation, honeybee honey is more preferred, as the overall scores (5.5 vs 4.8 ) including colour (4.5 vs 3.5), odour (5.2 vs 4.0 ) and sweetness (6.0 vs 3.5) were significantly higher than stingless bee honey, even though the aftertaste $(5.8$ vs 4.8$)$ is also higher. Furthermore, stingless bee honey has lower GI and GL $(81.76,5.27)$ as compared to honeybee honey $(97.86,6.96)$, respectively. It is suggested that the serving in term of odd or even numbers might affect the outcomes of the study as honeybee honey represents four spoons vs five spoons of stingless bee honey.
\end{abstract}

\section{Introduction}

Honey is defined as the sweet substance produced by honeybees from the nectar of blossoms which bees collect in a honeycomb (Iftikhar et al., 2011). According to Chaiyasut et al. (2018), typical honey has the following composition: fructose $(38.0 \%)$, glucose $(31.0 \%)$, sucrose $(1.0 \%)$, water $(17.0 \%)$ and others (3.3\%). Some international honey organization such as Codex Alimentarius and the International Honey Commission (IHC) have set standards to control this important natural food of honey (Eteraf-Oskouei and Najafi, 2013). The quality of honey depends on the type of flowers from which bees collect the nectar (Abdulkhaliq and Swailah, 2016).

There are two different types of honey produced by honeybee (Apis mellifera) and the stingless bee (Meliponini) (Erejuwa et al., 2012). Apis mellifera is the most widespread species of honeybee in the world and is mainly found in Europe, while Meliponina species are available in tropical regions (Kek et al., 2017). Stingless 
bee honey is multi-floral honey which is stored in clusters of small resin pots near the extremities of their nests (Kek et al., 2014) and this honey is limited in the world market compared with honeybee honey because there is a lack of quality control parameters and no safety assurance for its consumption (Guerrini et al., 2009). The moisture content of stingless bee honey is generally higher than that of the honeybee honey (D Silva et al., 2013). However, stingless bee honey is resistant to unwanted fermentation because it contains polyphenolic that can protect the oxidation process (Nordin et al., 2018). On the other hand, honeybee honey is produced by honeybees (Apis) species, stored in hexagonal shape hives. All quality criteria of honey are described by law include the quality control of honey and the rules on the marketing and production of honey (Vranic et al., 2017).

The honey composition is related to several factors that have a direct effect on its composition and quality. These include bee species, floral origin, environmental and storage conditions (De-Melo, 2017). The physicochemical parameters are also important indicators for the analysis of honey quality standards and include moisture content, ash content, $\mathrm{pH}$, free acidity, electrical conductivity and sugar content (Iftikhar et al., 2011). The colour and flavour of honey vary depending on the nectar sources or the blossoms encountered by honeybees (Scholz et al., 2020). Sensory evaluation enables researchers to distinguish the botanical origin of the honey and to identify and quantify certain defects, such as fermentation, impurities, off-odours and flavours (Saludin et al., 2019).

Sensory evaluation is a scientific discipline that analyses the responses of humans to the composition of food and drink in terms of appearance, touch, odour, texture, temperature and taste (Saludin et al., 2019). This analysis corresponds to consumer perceptions, acceptance and complements in the determination of botanical origin and physicochemical characteristics, which also help determine consumer preferences towards products. Familiarity with honey has been shown to influence descriptions, acceptance and also preference expressed during the sensory evaluation, but who are less familiar with honey usually focus on overall acceptability above individual sensory properties (Prica et al., 2014).

Generally, fructose tends to lower blood glucose response in animal models diabetes (Bobiş et al., 2018). The glycemic index (GI) is a measure of the effect that a carbohydrate-containing food has on blood sugar levels, compared to the effect of the same amount of pure sugar. Foods are categorized into three groups in the GI: low $(<55)$, medium (55-69) and high $(>70)$ (Eleazu, 2016).
According to International Honey Commission (2009), honey has a low to moderate GI ranging from 32 to 64 , depending on the botanical source. Low GI foods are more beneficial for people who are on a diet as they help with satiety aiding them in controlling their total food consumption (Chang et al., 2012). Until recently, the health benefit potential of stingless bee honey in medical databases are still scarce as compared to honeybee honey, which is popular for its properties as a therapeutic agent (Amin et al., 2018). Carbohydrate monitoring remains a key strategy in achieving the glycemic control in diabetic patients and the use of the glycemic index and glycemic load may provide a modest additional benefit to them. High GI raises blood sugar levels but GI does not take into account the amount of carbohydrate in a food. Thus, glycemic lead (GL) is a better indicator of how a carbohydrate food will affect blood sugar levels. Furthermore, the higher the fructose content, the lower the GI of honey which depends on the different types of honey (Krishnasree and Ukkuru, 2017). Based on the physicochemical profiles and sensory evaluation of stingless bee honey and honeybee honey, the present study aimed to demonstrate whether stingless bee honey or honeybee honey is better for diabetic patients.

\section{Materials and methods}

\subsection{Physicochemical characterization of honey samples}

Samples of stingless bee honey and honeybee honey were obtained from a local honey farm in Marang, Terengganu. Physicochemical parameters including moisture, ash, $\mathrm{pH}$, free acidity and electrical conductivity (EC) were determined according to the methods described by International Honey Commission (2009) following the International Honey Commission (2009).

\subsection{Determination of moisture and ash content}

Moisture and ash content were determined according to the methods of the International Honey Commission (2009). For moisture content, the refractive index of the honey was determined using a digital refractometer (NR 101 Spain). Meanwhile, ash content was determined by placing $5 \mathrm{~g}$ of honey in combustion pots, which required preheating to darkness with a gas flame to prevent honey foaming. Then, the samples were incinerated at a high temperature $\left(550^{\circ} \mathrm{C}\right)$ in a burning muffle for $5 \mathrm{~h}$. After cooling at room temperature, the obtained ash was weighed.

\subsection{Determination of $p H$, free acidity and electrical conductivity (EC)}

The $\mathrm{pH}$ levels were measured and the solution was titrated with $0.1 \mathrm{M}$ sodium hydroxide solution to $\mathrm{pH}$ 
8.30. The $\mathrm{pH}$ meter was calibrated at $\mathrm{pH} 3.0,7.0$ and 9.0. Then, $10 \mathrm{~g}$ of each sample was dissolved in $75 \mathrm{~mL}$ of carbon dioxide-free water in a $250 \mathrm{~mL}$ beaker. The magnetic stirrer was stirred and the $\mathrm{pH}$ electrodes were immersed in the solution.

The free acidity of honey is the sum of all the free acids expressed in milliequivalents per kilogram of honey. The samples $(10 \mathrm{~g})$ were dissolved in distilled water $(250 \mathrm{~mL})$ and titrated with $0.1 \mathrm{M}$ sodium hydroxide solution at $\mathrm{pH}$ (8.3) until the honey was dissolved in a beaker and stirred with a magnetic stirrer. The solution is then titrated with $0.001 \mathrm{M}$ sodium hydroxide solution to $\mathrm{pH} 8.3$. The free acidity, expressed in milliequivalents of acid per kilogram of honey, is equal to the volume of soda $0.01 \mathrm{M} \times 1000$.

The electrical conductivity was determined according to the method described by International Honey Commission (2009) using a conductometer (Cond 3210 WTW). The measurements were carried out at $20^{\circ} \mathrm{C}$ in a $20 \%$ aqueous solution with respect to the dry matter of honey. The value of conductivity was directly determined by the cell in the solution after immersion. The results were expressed in micro-Siemens per centimetre $(\mathrm{mS} / \mathrm{cm})$.

\subsection{Determination of sugar by HPLC}

Sugar levels were analyzed using HPLC with RID detector following the method of International Honey Commission, 2009 (IHC). The analysis was done at IMR, Kuala Lumpur.

\subsection{Sensory evaluation}

The determination of panellist reactions towards and preferences for the samples under standardized and controlled conditions of the sensory evaluation was conducted in this section. Ten untrained panellists among the subjects of a GI study evaluated the samples. A seven -point hedonic scale had been used in this evaluation test. The score was ranking between 1 which determined the preferences of panellist dislike extremely and 7 for like extremely. The attributes that the panellist evaluated included colour, odour, sweetness, sourness, aftertaste, texture and overall acceptance (Seema and Katare, 2013). Honey samples were weighed $(0.3 \mathrm{~g})$ and prepared in a small spoon.

\subsection{Glycemic index testing protocol}

The protocol used to determine the GI value of raw stingless bee honey and honeybee honey samples followed the International Organization for Standardization ISO 26642: 2010(E) (International Organization for Standardization, 2010). A total of 10 subjects (all female) participated in the GI study (Chepulis and Francis, 2012). The age of all subjects ranged from 18-25 years old (Radwan et al., 2018). Bodyweight and height were taken to calculate BMI. The range of BMI of subjects that were involved in this study was $19.5-26.5 \mathrm{~kg} / \mathrm{m}^{2}$. Subjects were also free from diabetes and did not suffer from other chronic diseases such as cirrhosis, cardiovascular disease, cancer and mental disorder. Furthermore, they had not participated in a clinical trial in the past three months. These screening methods are in line with standard GI testing criteria.

All subjects were subjected to an Oral Glucose Tolerance Test (OGTT) before recruitment to ensure that the subjects met the inclusion and exclusion criteria. The subjects were required to fast overnight for at least 10-12 hours (Radwan et al., 2018). The next morning, the subjects were given $50 \mathrm{~g}$ of glucose (Glucolin) dissolved in $250 \mathrm{~mL}$ water and the blood glucose was been taken at 120 mins. The subject who fulfilled the inclusion criteria was selected. For the glycemic index study, subjects were initially given $25 \mathrm{~g}$ pure glucose that was dissolved in $250 \mathrm{ml}$ of water. Blood glucose were determined by using test strips, taken at each time point $(0,30,60,120$ mins). For the honey as test samples, the same procedure was followed. Subjects were given $25 \mathrm{~g}$ of carbohydrate in honey that was dissolved in $250 \mathrm{~mL}$ of water. Thus, $38.86 \mathrm{~g}$ of raw honeybee honey and $49.64 \mathrm{~g}$ of raw stingless bee honey were applied.

GI and GL were calculated following the recommendation from Food and Agriculture Organization/World Health Organization (1998).

$$
\begin{gathered}
\text { GI }=\frac{\text { AUC for test food }}{\text { AUC for reference food }} \times 100 \\
\mathrm{GL}=\frac{\text { GI of carbohydrate } \mathrm{x} \text { grams of carbohydrate per serving food }}{100}
\end{gathered}
$$

\subsection{Statistical analysis}

The triplicate data obtained were presented as mean \pm standard deviation. Independent t-test and one-way ANOVA with post-hoc Tukey's were performed using Statistical Package for the Social Science (SPSS) version 16 software. In all analysis, $\mathrm{p}<0.05$ was taken to indicate significance.

\section{Results and discussion}

3.1 Physicochemical properties of raw stingless bee honey and raw honeybee honey

Physicochemical parameters are important indicators for the analysis of honey quality standards. The parameters include $\mathrm{pH}$, acidity, electrical conductivity, water content, ash and sugar composition and different 
types of honey related to different properties depend on the botanical origin, floral source, season, weather, storage method and treatment of honey by the bee (Vranic et al., 2017).

The moisture content of raw honeybee honey from Malaysia ranged between 21.96-33.24 g/100 g, higher than the limit of Codex Standard of honey, which is less than 20\% (Kek et al., 2018). The moisture content of raw Apis dorsata of honeybee species of honey from India was $23.1 \%$, and $27.8 \%$ from the Philippines, while that from Malaysia is usually also $22.21 \%$ (Qamer et al., 2008), and raw stingless bee honey was found to be $33.24 \mathrm{~g} / 100 \mathrm{~g}$ (Kek et al., 2018). In the present study, since both kinds of honey were obtained from a similar area, which shares same geographical characteristics including temperature, source of fruit and flower, the moisture content of raw honeybee honey and raw stingless bee honey are very similar.

Determination of ash content offers the possibility of determining the overall mineral content in honey (Kek et al., 2018). The ash content of honey is related to its mineral content and also influenced by the composition of the source of plant nectar. In the present study, the ash content for stingless bee honey was $0.25 \mathrm{~g} / 100 \mathrm{~g}$ while honeybee honey was $0.32 \mathrm{~g} / 100 \mathrm{~g}$, as shown in Table 1 . Similar to moisture content, no significant differences were found in ash content between raw stingless honeybee and honeybee honey $(p>0.05)$. It can be concluded that even though the honey type is different, their ash content is closely similar, which might due to similar geographical source (Marang area). The rich of ash content of honey is related to the rich content of pollen source surrounding the apiary yard during honey production (Sohaimy et al., 2015). The ash content of raw stingless bee honey was found between $0.15 \pm 0.01$ and $0.67 \pm 0.00 \mathrm{~g} / 100 \mathrm{~g}$ (Bakar et al., 2017) while the ash content of raw $A$. dorsata species of honeybee honey was higher $(1.02 \%)$ and it is was found to be accompanied by an increase in electrical conductivity (Krishnasree and Ukkuru, 2017). The ash content of honey is attributed qualitatively to different botanical and geographical origins, which affect the amount of trace mineral in honey (Bakar et al., 2017).

Honey is acidic in nature, and $\mathrm{pH}$ values of Malaysian raw honey varied from 3.22 to 3.74 (Kek et al., 2018). The free acidity of honey contributes to the presence of organic acids in honey. High acidity may indicate the fermentation of sugars into organic acids (Nordin et al., 2018). In the present study, the $\mathrm{pH}$ of raw honeybee honey was 3.25 and raw stingless bee honey was 3.19 and thus, both kinds of honey were more acidic. The $\mathrm{pH}$ value for stingless bee honey was not significantly different $(\mathrm{p}>0.05)$ with honeybee honey and the value is closely similar which might due to similar geographical source of Marang area. According to the previous study, the $\mathrm{pH}$ of raw stingless bee honey was in ranged 2.90 to 3.83 while $\mathrm{pH}$ of honeybee species was $3.74 \pm 0.23$. The lower $\mathrm{pH}$ values of stingless bee honey may inhibit the presence and growth of microorganisms (Kek et al., 2017).

Table 1. The physicochemical properties of raw stingless bee honey and honeybee honey

\begin{tabular}{lcc}
\hline \multicolumn{1}{c}{$\begin{array}{c}\text { Physicochemical } \\
\text { properties }\end{array}$} & Stingless bee honey & Honeybee honey \\
\hline Moisture (\%) & 28 & 29.5 \\
Ash $(\%)$ & $0.25 \pm 0.02^{\mathrm{a}}$ & $0.32 \pm 0.19^{\mathrm{a}}$ \\
Sugar $(\%)$ & 50.35 & 64.33 \\
pH & $3.190 \pm 0.006^{\mathrm{a}}$ & $3.250 \pm 0.025^{\mathrm{a}}$ \\
Free acidity (meq/kg) & $73.50 \pm 2.18^{\mathrm{b}}$ & $84.50 \pm 3.96^{\mathrm{a}}$ \\
$\begin{array}{l}\text { Electrical conductivity } \\
\text { (mS/cm) }\end{array}$ & $0.79 \pm 0.02^{\mathrm{a}}$ & $0.77 \pm 0.68^{\mathrm{a}}$ \\
\hline
\end{tabular}

Values are expressed as mean \pm SEM. Values with different letter superscript indicate significant difference $(p<0.05)$ by using Independent T-test.

Lower $\mathrm{pH}$ values indicate the more acidity, more hydrogen ion and higher ability to inhibit the growth of bacteria (Fatima et al., 2015). Colour of honey also could be one of the factors of higher in acidity in honey because the darker of honey, in general, appear to be higher in acidity (Prica et al., 2014). There was a significant difference in free acidity between stingless bee honey and honeybee honey (73.5 vs $84.5, \mathrm{p}<0.05)$. Even though moisture content and $\mathrm{pH}$ were not significantly different, the free acidity of honeybee honey was significantly higher than stingless bee honey, indicating higher probability to undergo fermentation of sugar to occur. This is because the higher moisture content related to the higher acidity content in honey contributes to the fermentation of sugar (Prica et al., 2014). The free acidity of raw honeybee honey was higher, but this does not mean this honey undergoes fermentation process because the honey is freshly harvested. Freshly extracted honey is a viscous liquid, and its viscosity depends on a large variety of substances and therefore varies with its composition and particularly with its water content (Eteraf-Oskouei and Najafi, 2013). It has been reported that the free acidity of raw stingless bee honey is $136.8 \mathrm{meq} / \mathrm{kg}, 2.7$ times significantly higher than other Apis spp. honey $(<55.0 \mathrm{meq} / \mathrm{kg})$ while raw $A$. dorsata honeybee species was in $54.9 \pm 7.0 \mathrm{meq} / \mathrm{kg}$ (Kek et al., 2017). However, a majority of stingless bee honey with available free acidity data complies with the standards by the IHC value of not more than $50 \mathrm{meq} / \mathrm{kg}$ (Nordin et al., 2018).

The electrical conductivity of honey is closely related to the concentration of the mineral salts, organic 
acid and proteins. Honey produced during the rainy season had higher water content, higher $\mathrm{pH}$ and was also higher in electrical conductivity (Azonwade et al., 2018). In the present study, there were no significant differences in electrical conductivity of raw stingless bee honey between raw honeybee honey $(p>0.05)$. It can be concluded that even though the honeybee type is different, their ash content is closely similar which might due to a similar geographical source attributed to the similar electrical conductivity value. Electrical conductivity measurements depend on the ash content and acidity content of honey. Higher ash content is related to higher electrical conductivity (Namini et al., 2018).

Other studies have reported that the range of electrical conductivity for raw $A$. dorsata honeybee species ranged from $0.22 \mathrm{mS} / \mathrm{cm}$ to $0.96 \mathrm{mS} / \mathrm{cm}$ (Qamer et al., 2008) while raw stingless bee honey ranged within 0.96 to $1.22 \mathrm{mS} / \mathrm{cm}$ (Kek et al., 2017). Electrical conductivity is related to concentration of mineral, salt, organic acid and protein which is an aqueous solution that can dissociate into ions or to conduct an electrical power (Namini et al., 2018).

Carbohydrates in the form of sugars are the major constituents of honey (Nordin et al., 2018). According to the standards by IHC, good quality honey should have a sum of both fructose and glucose which is not less than $60 \mathrm{~g} / 100 \mathrm{~g}$ (Nordin et al., 2018). In the present study, the carbohydrate in raw stingless bee honey was $50.35 \mathrm{~g} / 100$ $\mathrm{g}$, lower than honeybee honey of $64.33 \mathrm{~g} / 100 \mathrm{~g}$ as shown in Table 2. The higher total reducing sugar in honeybee honey might be attributed to its higher acidity content (Bakar et al., 2017). In agreement with the present study, free acidity raw honeybee honey was higher which attributes to the higher total carbohydrate content. In another study, carbohydrate analysis of raw Malaysia stingless bee honey values ranged from $67.20 \pm 0.11$ to $72.01 \pm 0.35 \mathrm{~g} / 100 \mathrm{~g}$ (Bakar et al., 2017). The higher carbohydrate content in honey indicates that it was a main constituent of honey, and about $90 \%$ of honey's dry weight (Bakar et al., 2017). While for the reducing sugar

Table 2. Sugar profile of raw stingless bee honey and honeybee honey

\begin{tabular}{lcc}
\hline \multicolumn{1}{c}{ Sample $(\mathrm{g} / 100 \mathrm{~g})$} & Stingless bee honey & Honeybee honey \\
\hline Fructose & 24.27 & 32.24 \\
Glucose & 23.75 & 29.56 \\
Sucrose & 1.51 & 1.04 \\
Maltose & 0.74 & 1.22 \\
Lactose & 0.06 & 0.24 \\
Total & 50.35 & 64.33 \\
\hline
\end{tabular}

Values are expressed as mean \pm SEM. Values with different letter superscript indicate significant difference $(p<0.05)$ by using Independent T-test. of raw honeybee honey was ranged from $33.03 \%$ to $67.60 \%$ and for $A$. dorsata species was $62.10 \%$ while total sugar of raw $A$. dorsata species was $68.75 \%$ and the lowest sucrose content was reported in A. dorsata species was $5.31 \%$. The higher sucrose content in certain honey may also be caused by a lack of conversion of sucrose by the bees (Krishnasree and Ukkuru, 2017).

\subsection{Sensory evaluation of honey}

Sensory evaluation is a scientific discipline that analyses the responses of humans to the composition of food and drinks such as appearance, touch, odour, texture, temperature and taste. For honey, sensory evaluation enables us to distinguish the botanical origin of the honey and to identify and quantify certain defects (fermentation, impurities, off-odours and flavours) (Saludin et al., 2019). Figure 1 shows the sensory evaluation of both kinds of honey.

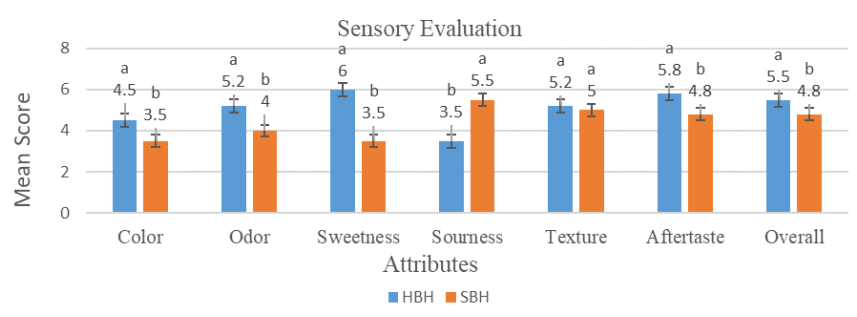

Figure 1. Sensory evaluation of test honey. Values with different letter superscripts are significant different $(p<0.05)$ by using Independent T-test

Colour of honey is the first quality appearance judgement that affects consumer preference. In the present study, there was a significant difference in colour between honeybee honey and stingless bee honey $(p<0.05)$ which indicated that honeybee honey is more preferred by the respondents. This might due to dark colour of honeybee honey, as dark honey is preferred by consumers because honey with a dark colour have a higher mineral and antioxidant capacity (Kek et al., 2017). The colour of honey is related to the floral origin or plant source, minerals, phenolic contents, storage time and temperature (Saludin et al., 2019).

For odour of honey, the panellist more prefers honeybee honey. There was a significant difference in odour between honeybee honey and stingless bee honey $(\mathrm{p}<0.05)$. Usually, appearance, odour or aroma, texture and flavour are the attributes that consumers used to perceive the foods. The odour of honey is one of its most typical features and consumers often determine their selection of honey products according to this character (Yang et al., 2017). Distinctive flavour and odour features were found among different honey types because of their different origins and characteristic volatile compositions (Yang et al., 2017). 
There was a significant difference of sweetness and sourness between honeybee honey and stingless bee honey $(p<0.05)$ in terms of sweetness, while stingless bee honey is higher in sourness. Thus, even though the $\mathrm{pH}$ levels are similar for both honey $(3.25,3.19)$ as shown in Table 1, the tastes (sweet or sour) are significantly different, as shown in Figure 1 . This is the importance of sensory analysis in combination with the physicochemical determination to evaluate the customer's preference. Stingless bee honey has lower sugar content, which influences its less-sweet and moresour taste (Azri et al., 2017). In the present study, sugar profile honeybee honey was higher as compared to stingless bee honey. Furthermore, there is a claim that stingless bee honey is better due to its sour taste, which needs further investigation but indicating low total sugar than honeybee honey (Azri et al., 2017). Then, there was no significant difference in the texture between two of honey $(\mathrm{p}>0.05)$. There was a significant difference in the aftertaste between stingless bee honey and honeybee honey $(p<0.05)$ and for the overall acceptance of honeybee honey was significantly higher as compared to stingless bee honey $(\mathrm{p}<0.05)$.

\subsection{Glycemic index (GI)}

Figure 2 shows the GI of the honey and glucose. Honeybee honey and stingless bee honey had varying effects on GI. According to Bodganov et al. (2008), honey has a low to moderate GI ranging from 32 to 64 depending on the botanical source. However, in the present study, the GI of honey was ranged from 81.76 to 97.86. Glucose is the simplest form of sugar and gives the highest GI which is equal to 100 . Guevarra and Panlasigui (2000) showed that the GI of fructose is 23, while those of sucrose and glucose are 61 and 100, respectively. According to Krishnasree and Ukkuru (2017), raw honeybee honey has a higher GI at 61 than GI of raw stingless bee honey at 54 . In the present study, the GI values of both kinds of raw honey were higher from their range GI value. Based on a previous study, the maximum GI of raw honeybee honey ranges from 69.1 to 109.0 because the chemical constituents of honey are not constant, varying according to botanical and geographical origins (Atayoglu et al., 2016).

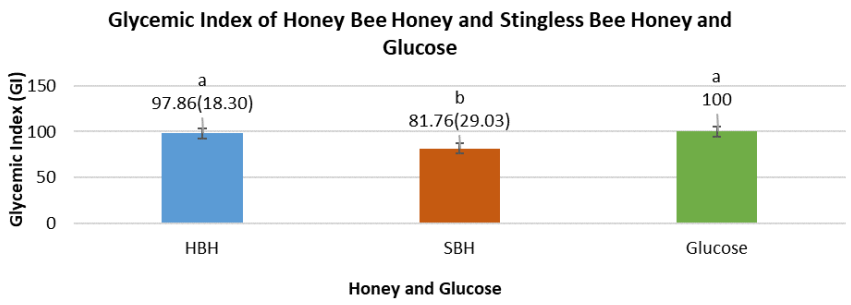

Figure 2. The glycemic index (GI) of the honey and glucose. Values are mean (SEM) with different letter superscripts are significantly difference $(\mathrm{p}<0.05)$ by using One-way ANOVA
Fructose tends to lower blood glucose and it may include a reduced rate of intestinal absorption, prolongation of gastric emptying time and reduced food intake. Fructose stimulates glucokinase in hepatocytes, which plays an important role in the uptake and storage of glucose by the liver. Glucose, on the other hand, is present beside fructose in honey, and enhances the absorption of fructose and promotes its hepatic actions through its enhanced delivery to the liver (Bobis et al., 2018). In the present study, the GI levels of honeybee honey (97.86) and stingless bee honey (81.76) were significantly different $(p<0.05)$ because the honeybee honey had fructose and glucose levels which were higher than those of stingless bee honey. Another factor that might influence GI is the dose of honey used for the respondents during the test ( $38.86 \mathrm{~g}$ vs $49.64 \mathrm{~g}$ ). The amount of honeybee honey was lower than stingless bee honey, but the GI of honeybee honey is higher than stingless bee honey. Table 3 shows the amount of honey used during the test. It is postulated that not the amount of honey responsible for the GI value, but the number of dosages in term of household measurement spoon in odd or even number might be a factor that contributes to these differences.

Table 3. The amount of dose honey that use during the test

\begin{tabular}{lcc} 
Sample $(\mathrm{g} / 100 \mathrm{~g})$ & Stingless bee honey & Honeybee honey \\
\hline Fructose & 12.05 & 12.53 \\
Glucose & 11.79 & 11.49 \\
Sucrose & 0.75 & 0.40 \\
Maltose & 0.36 & 0.47 \\
Lactose & 0.03 & 0.09 \\
Total & 24.98 & 24.98
\end{tabular}

Amount of honey $(25 \mathrm{~g} \quad 49.64 \mathrm{~g}=5$ spoons $\quad 38.86 \mathrm{~g}=4$ of available of of honey spoons of honey

Values are expressed as mean \pm SEM. Values with different letter superscript indicate significant difference $(p<0.05)$ by using Independent T-test.

Our unpublished study shows that there was a relationship between honey consumption with an odd number of spoons and honey consumption with even number of spoons to the blood glucose response. From that study, the results showed better and more significant outcomes for honey consumption in an odd number of spoons rather than an even number. In Islamic medical system, several Sahabah (radiyallahu'anhum) have reported that Rasulullah (sallallahu 'alayhi wasallam) said: Indeed Allah Ta'ala is one (which is an odd number) and He loves the odd number (At- Tirmidhi, 2007) from Hadith: 453 and Musnad Ahmad. Imam Tirmidhi (rahimahullah) has declared his narration as sound (hasan). Anas also narrated: The Prophet used to eat odd number of dates (al- Bukhari, 1314H). It is proven that the Prophet (blessings and peace of Allah be 
upon him and his family) would not go out for prayer on the Day of Eid al-Fitr until he had eaten an odd number of dates.

Glycemic load (GL) values for the same food can be determined with the known GI value of that particular food. GL represents both the quality and quantity of the carbohydrate consumed. GL was used to overcome the shortcoming of GI, the amount of ingested food was taken into consideration. GL was defined as GI times grams of carbohydrate divided by 100 when applied to individual foods (Colombani, 2004). Each unit of dietary GL represents the equivalent glycemic effect of $1 \mathrm{~g}$ of carbohydrate from reference food (Willet et al., 2002). Figure 3 below shows the glycemic load of honey and glucose.

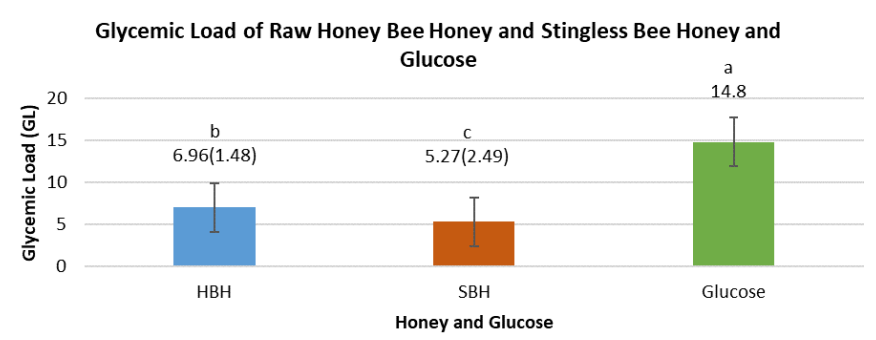

Figure 3. The glycemic load of the honey and glucose. Values are mean (SD) with different letter superscripts are significant difference $(\mathrm{p}<0.05)$ by using One-way ANOVA

A significant difference was found in GL between honeybee honey (6.96) and glucose (14.8) ( $>0.05)$ which were also significantly higher than stingless bee honey (5.27) $(p<0.05)$. The significant difference for honey and glucose could be due to glucose is medium GL food while honeybee honey and stingless bee honey can be categorized as low GL food since the GL values are less than 10. A previous study showed that carbohydrates with high glycemic load produce substantial postprandial blood glucose and insulin responses. Blood glucose declines rapidly after consumption due to secretion of insulin within a few hours, thus creates a state of hunger (Bell and Sears, 2003).

Thus, it can be concluded that differences in GI might be caused by different doses of each honey used and the sugar content in the honey. Based on the previous study, the GL, GI and serving size of raw honeybee honey was 12.35 vs 61 vs $20 \mathrm{~g}$, while those of stingless bee honey was 11.88 vs 54 vs $20 \mathrm{~g}$ (Krishnasree and Ukkuru, 2017). However, in the present study, the GL, GI and serving size of raw honeybee honey was (6.96 vs 97.86 vs $10 \mathrm{~g}$ ) and raw stingless bee honey was 5.27 vs 81.76 vs $10 \mathrm{~g}$, with better GL reported in the present study.

\section{Conclusion}

From the physicochemical analysis, there was a significant difference in term of moisture content, free acidity, and total sugar of raw honeybee honey and raw stingless bee honey $(\mathrm{p}<0.05)$ while no significant difference for ash content, $\mathrm{pH}$ and electrical conductivity of both kinds of honey $(\mathrm{p}>0.05)$. Though the honeybee types differ, there share a similar geographical source. In terms of sensory evaluation, raw or unprocessed honeybee honey is more preferred, as the overall scores including colour, odour and sweetness were significantly higher than those of stingless bee honey, even though the aftertaste is also higher. The glycemic index (GI) for honeybee honey was 97.86 while that of stingless bee honey was 81.76 . There was a significant difference of GI between honeybee honey and stingless bee honey $(p<0.05)$. However, the glycemic load (GL) of honeybee honey was 6.96 and stingless bee honey was 5.27 , both are categorized as low GL. Therefore, this study shows that raw stingless bee honey can be eaten in moderate amounts by diabetic patients provided that honey is within the carbohydrate allowance of not more than five spoons. Further studies should be carried out to verify the effect of a higher amount, ie more than $50 \mathrm{~g}$ of carbohydrate of honey, on GI and GL.

\section{References}

Abdulkhaliq, A. and Swaileh, K.M. (2016). Physicochemical properties of multi-floral honey from the West Bank, Palestine. International Journal of Food Properties, 20(2), 447-454. https:// doi.org/10.1080/10942912.2016.1166128

Amin, F.A.Z., Suriana, S., Mohammad, S.M., Ismail, M., Chan, N., Mohd, E.N. and Norhasnida Z. (2018). Therapeutic properties of stingless bee honey in comparison with European bee honey. Advances in Pharmacological Sciences, 2018, 6179596. https:// doi.org/10.1155/2018/6179596

Atayoglu, A.T., M. Soylu, S. Silici and Inanc, N. (2016). Glycemic index values of monofloral Turkish honey and the effect of their consumption on glucose metabolism. Turkish Journal Medicial Science, 46, 483-488. https://doi.org/10.3906/sag-1502-102

Azonwade, F.E., Paraiso, A., Dossa, C.P.A., Dougnon, V.T., N'tcha, C., Mousse, W. and Baba-Moussa, L. (2018). Physicochemical characteristics and microbiological quality of honey produced in Benin. Journal of Food Quality, 2018, 1896057. https:// doi.org/10.1155/2018/1896057

Azri, M., Hadi, H. and Kasmuri, A.R. (2017). Stingless bee honey, the natural wound healer: A review. Skin Pharmacology and Physiology, 30(2), 66-75. https:// doi.org/10.1159/000458416 
At-Tarmidhi, M.I.E. (2007). Jami' At-Tarmidhi. Vol. 4., p. 580.Riyadh: International Online Store of Darussalam Publishers.

Bodganov, S., Sieber, R., Jurendic, T. and Gallmann, P. (2008). Honey for nutrition and health: A review. Journal of the American College of Nutrition, 27(6), 677-689. doi.org/10.1080/07315724.2008.10719745

International Honey Commission. (2009). Harmonised Methods of the International Honey Commission. Retreived from International Honey Commission website: ihcmethods2009.pdf https://www.ihc-platform.net/

Bakar, M.F.A., Sanusi, S.B., Bakar, F.I.A, Cong, O.J. and Mian, Z. (2017). Physicochemical and antioxidant and potential of raw unprocessed honey from Malaysian stingless bees. Pakistan Journal of Nutrition, 16(1), 888-894. https://doi.org/10.3923/ pjn.2017.888.894

Bell, S.J. and Sears, B. (2003). Low glycemic load diets. Impact on obesity and chronic diseases. Critical Review in Food Science and Nutrition, 43(4), 357377. https://doi.org/10.1080/10408690390826554

Bobis, O., Dezmirean, D.S. and Moise, A.R. (2018). Honey and Diabetes. The importance of natural simple sugars in diet for preventing and treating different type of diabetes. Oxidative Medicine and Cellular Longevity, 2018, 4757893. https:// doi.org/10.1155/2018/4757893

Chaiyasut, C., Kesika, P., Peerajan, S. and Sivamaruthi, B.S. (2018). Total polyphenolic content and antioxidant properties of various honey and sugars. Asian Journal of Pharmaceutical and Clinical Research, 11(5), 467-471. https://doi.org/10.22159/ ajpcr.2018.v11i5.24696

Chang, K.T., Lampe, J.W. and Neuhouser, M.L. (2012). Low glycemic load experimental diet more satiating than high glycemic load diet. Nutrition and Cancer, 64(5), 666-673. doi.org/10.1080/01635581.2012.676143

Chepulis, L. and Francis, E. (2012). The glycemic index of Manuka honey. e-SPEN Journal, 8(1), e21-e24. https://doi.org/10.1016/j.clnme.2012.11.002

Colombani, P. (2004). Glycemic index and loadDynamic dietary guidelines in the context of disease. Physiology and Behavior, 83(4), 10-603. https:// doi.org/10.1016/j.physbeh.2004.07.029

D. Silva, I.A.A., Da Silva, T.M.S, Camara, C.A., Queiroz, N., Magnane, M. and De Novais, J.S. (2013). Phenolic profile, antioxidant activity and palnological analysis of stingless bee honey from Amazonas, Northern Brazil. Food Chemical, 141(4),
3552-3558.

https://doi.org/10.1016/

j.foodchem.2013.06.072

Eleazu, C.O. (2016). The concept of low glycemic index and glycemic load foods as panacea for type 2 diabetes mellitus; prospects, challenge and solutions. African Health Science, 16(2), 468-479. https:// doi.org/10.4314/ahs.v16i2.15

Erejuwa, O., Sulaiman, S., Wahab, M., Sirajudeen, K., Salleh, M. and Gurtu, S. (2012). Hepatoprotective effect of tualang honey supplementation in streptozotocin-induced diabetic rats. International Journal of Applied Research in Natural Products, 4 (4), 37-41.

Eteraf-Oskouei, T. and Najafi, M. (2013). Traditional and modern uses of natural honey in human disease: A review. Iranian Journal of Basic Medical Science, 16(6), 731-742.

Fatima, I.J., Hilmi, A.B., Salwani, I. and Lavaniya, M. (2015). Physicochemical characteristics of Malaysian Stingless bee honey from Trigona species. Food Science, 187-191.

Guerrini, A., Bruni, R. Maietti, S. Poli, F. Rossi, D. Paganetto, G. and Sacchetti, G. (2009). Ecuadorian stingless bee (Meliponinae) honey: A chemical and functional profile of an ancient health product. Food Chemistry, 11(4), 1413-1420. https:// doi.org/10.1016/j.foodchem.2008.11.023

Guevarra, M.T.B and Panlasigul, L.N. (2000). Blood glucose response of diabetes mellitus type II patients to some local fruits. Asia Pacific Journal Clinical Nutrition, 9(4), 303-308. https://doi.org/10.1046/ j.1440-6047.2000.00159.x

Iftikhar, F., Masood, M.A. and Waghchoure, E.S. (2011). Comparison of Apis Cerana, Apis Dorsata, Apis Florea and Apis Mellifera honey from different areas of Pakistan. Asian Journal Experiment Biological Science, 2(3), 399-403.

International Organization for Standardization. (2010). Food products - Determination of the glycemic index (GI) and recommendation for food classification ISO26642:2010(E). Geneva, Switzerland: ISO.

Krishnasree, V. and Ukkuru, P.M. (2017). Quality analysis of bee honey. International Journal Current Microbiological Application Science, 6(2), 626-636. https://doi.org/10.20546/ijcmas.2017.602.071

Kek, S.P., Chin N.L., Yusof, Y.A., Tan, S.W. and Chua, L.S. (2014). Total phenolic contents and colour intensity of Malaysian honey from the Apis spp. and Trigona spp. Bees. Agriculture and Agricultural Science Procedia, 2, 150-155. https:// doi.org/10.1016/j.aaspro.2014.11.022

Kek, S.P., Chin, N.L.,Tan, S.W., Yusof, Y.A. and Chua, 
L.S. (2017). Classification of honey from its bee origin via chemical profiles and mineral content. Food Analytical Methods, 10(1), 19-30. https:// doi.org/10.1007/s12161-016-0544-0

Kek, S.P., Yusof, Y.A., Chin, N.L. and Tan, S.W. (2018). Classification entomological origin of honey based on its physicochemical and antioxidant properties. International Journal of Food Properties, 1532-2386.

Nordin, A., Sainik, N.Q.A.V., Chowdhurry, S.R., Saim, A. B. and Idrus, R.B.H. (2018). Physicochemical properties of stingless bee honey from around the globe: A comprehensive review. Journal of Food Composition and Analysis, 73, 91-102. https:// doi.org/10.1016/j.jfca.2018.06.002

Namini, Z., N., Mousavi, M.H., Mahmoudi, R. and Hassanzadeh (2018). Hygience quality of the honey samples produced in Iran in comparison with international standards. International Food Research Journal, 25(3), 982-988.

Prica N., Zivkov-Balos, M., Jaksic, S., Mihaljev, Z., Kartalovic, B., Babic, J. and Savic, S. (2014). Moisture and acidity as indicators of the quality of honey originating from Vojvodina region. Archiv Veterinarske Medicine, 7(2), 99-109. https:// doi.org/10.46784/e-avm.v7i2.135

Qamer, S., Ahmad, F., Latif, F., Ali, S.S. and Shakoori, A.R. (2008). Physicochemical analysis of Apis dorsata honey from Terai forests, Nepal. Pakistan Journal of Zoology, 40(1), 53-58.

Radwan, H., Hasan, H., Ballout, R.A. and Lessan, N. (2018). The epidomiology and economic burden of obesity and related cardiometabolic disorders in the United Arab Emirates: A Systematic Review and Qualitative Synthesis. Journal of Obesity, 2018, 2185942. https://doi.org/10.1155/2018/2185942

Scholz, M.B.D.S., Junior, A.Q., Delamuta, B.H., Nakamura, J.M., Baudraz, M.C., Reis, M.O., Kato, T., Pedroa, M.R., Dias, L.S., Dos Santos, D.T.R., Kitzberger, C.S.G. and Bianchin, F.P. (2020). Indication of the geographical origin of honey using its physicochemical characteristics and multivariate analysis. Journal of Food Science and Technology, 57(5), 1896-1903. https://doi.org/10.1007/s13197019-04225-3

Sohaimy, E., S.A., Masry, S.H.D. and Shehata, M.G. (2015). Physicochemical charateristics of honey from different origins. Annals of Agricultural Sciences, 60(2), 279-287. https://doi.org/10.1016/ j.aoas.2015.10.015

Saludin, S.F., Kamarulzaman, N.H. and Ismail, M.M. (2019). Measuring consumer's preferences of stingless bee honey (Meliponine honey) based on sensory characteristics. International Food Research Journal, 26(1), 225-235.

Seema, R. and Katare, C. (2013). Evaluation of honey incorporated food preparation on the basis of glycemic index and their advocacy in impared glucose tolerance. International Journal of Research in Ayurveda and Pharmacy, 4(5), 277-287. https:// doi.org/10.7897/2277-4343.04531

Vranic, D., Petronijevic, Stojanovic, J.D., Koricanac, V., Milijasevic, J.B. and Milijasevic, M. (2017). Physicochemical properties of honey from Serbia in the period 2014-2016. IOP Conference Series: Earth and Environmental Science, 85, 012058. https:// doi.org/10.1088/1755-1315/85/1/012058

Willet, W., Manson, J. and Liu, S. (2002). Glycemic index, glycemic load and risk of type 2 diabetes. The American Journal of Clinical Nutrition, 76(1), 274280. https://doi.org/10.1093/ajcn/76.1.274S

Yang, W., Tian, Y. and Miao, X. (2017). Longevity extension of worker honeybees (Apis mellifera) by royal jelly: optimal dose and active ingredients. Peer Journal, 5, e3118. https://doi.org/10.7717/peerj.3118 